\title{
Muscle rupture after minimal trauma of the spastic muscle: three case reports of patients with spinal cord injury
}

\author{
TJD Carpentier, C Kiekens and KHE Peers
}

Study design: Retrospective study of three cases.

Objectives: To report three cases of muscle rupture caused by minimal trauma in spinal cord injury (SCl) patients with severe spasticity and a literature review of the underlying mechanisms.

Setting: Department of Physical and Rehabilitation Medicine, University Hospitals Leuven, Belgium

Methods: Retrospective study of three cases of muscle ruptures in $\mathrm{SCl}$ patients with severe spasticity. All muscle lesions were diagnosed by ultrasound. Literature review (Pubmed) was performed to identify extrinsic and intrinsic risk factors.

Results: According to the literature and our clinical findings, several structural and mechanical alterations of the spastic muscle in combination with specific stretching during therapy or a transfer can cause a muscle rupture after minimal trauma.

Conclusion: To the authors' knowledge, this is the first report of muscle rupture due to spasticity in SCl patients. Altered mechanical properties of the spastic muscle in combination with extreme stretching may cause partial or complete ruptur. Although this is a rare complication of spasticity, medical staff and therapists should be aware of the risk factors in order to prevent and quickly identify muscle lesions.

Spinal Cord (2013) 51, 721-722; doi:10.1038/sc.2013.28; published online 16 April 2013

Keywords: spasticity; musculus semimembranosus; muscle rupture; spinal cord injury

\section{INTRODUCTION}

Important functional and structural changes occur in skeletal muscles, secondary to spasticity following spinal cord lesion.

Spasticity has a significant impact on the quality of daily life. Prevention of contractures due to spasticity is an important objective for patients with spasticity. To prevent contractures, physical therapy comprising intensive stretching is required. Antispasmodics are used to reduce hypertonia and to improve motor control.

\section{CASE REPORT}

A 49-year-old man suffering from an incomplete paraplegia T12 (AIS C) for 8 years presented with sudden pain, sensory disturbances, increased hypertonia, increased spasms in both legs and more difficult ambulation. He reported no recent trauma. The onset of the complaints was a transfer from a tractor. The patient was previously known to be affected by severe muscle spasms (modified Ashworth Scale 4). A blood analysis showed a leucocytosis of 13300 per 1 and C-reactive protein (CRP) levels of $36 \mathrm{mgl}^{-1}$, and there was a visible hematoma in the left thigh. Ultrasound demonstrated a subtotal rupture of the musculus semimembranosus (Figure 1). Given the functional implication for the walking ability of this patient, a surgical intervention was opted for (Figure 2). Postoperative rehabilitation was difficult. After 4 months, a notable muscle strength deficit and a reduced walking perimeter persisted. Given the strong hypertonia and hyperreflexia, antispasmodics were administered.

Two similar cases in SCI patients were previously treated at the rehabilitation center of the University Hospitals Leuven. A 27-year-old man with complete paraplegia T11 (AIS A) developed during initial rehabilitation a bilateral hematoma of the upper leg. This occurred after a physiotherapy session including hamstring stretching with exteded knee and hip flexion. After ultrasound imaging, the diagnosis of a bilateral $\mathrm{m}$. semimembranosus rupture was confirmed. The second case concerns a 42-year old man with a complete paraplegia T12 (AIS A), which occurred at the age of 25. He suddenly developed a hematoma of the right mid-lateral thigh after a wheelchair transfer. Blood analysis showed a white blood cell count of 4600 per 1 and CRP of $8 \mathrm{mgl}^{-1}$. Initially, diagnosis of a deep venous thrombosis was suggested, however, ultrasound imaging showed a partial rupture of the right adductor muscle. These two patients were totally wheelchair bound and had normal use of upper limbs.

All three patients took no related medications (for example, antispasmodics, anticoagulants or platelet antiaggregants).

\section{DISCUSSION}

Muscle rupture is a rare complication of chronic spasticity. To the best of our knowledge, this spasticity-related complication is not yet described in spinal cord injury patients. Two case reports of muscle rupture complication have been described; in a brain injury patient ${ }^{1}$ and a MS patient. ${ }^{2}$ In both cases, the patients had severe spasticity.

Muscle tear in spastic muscles is not only related to mechanical stretch or sudden spasm. Spasticity results in tendon reflex changes, but also several compensatory changes occur at the level of the muscle. The fibers of a spastic muscle are stiffer than normal muscles, and fail on a shorter sarcomere length during elongation. In the spastic muscle, there is a relative increase in type II fibers, ${ }^{3}$ it being more easily affected. Previous research on muscle pain after eccentric 

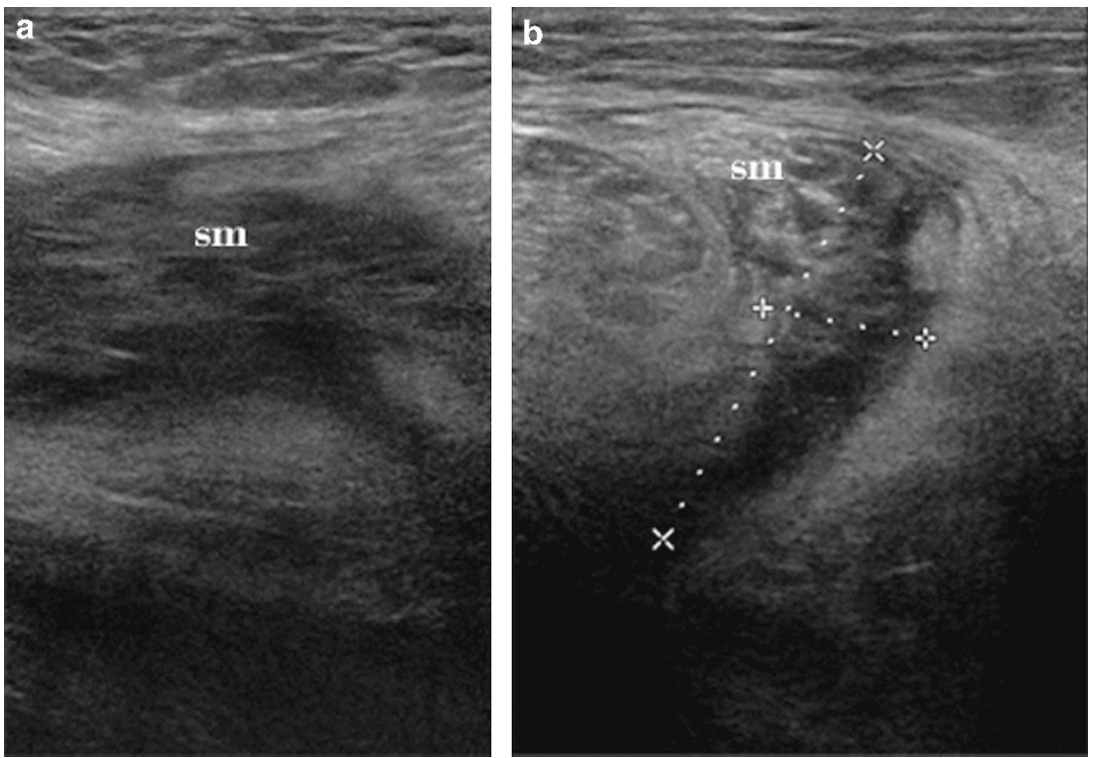

Figure 1 Sagittal (a) and axial (b) ultrasound images obtained over the proximal third of the $\mathrm{m}$. semimembranosus (sm) show a hypoechoic lesion measuring $4 \mathrm{~cm} \times 1.5 \mathrm{~cm}$, revealed as subtotal rupture of the $\mathrm{m}$. semimembranosus.

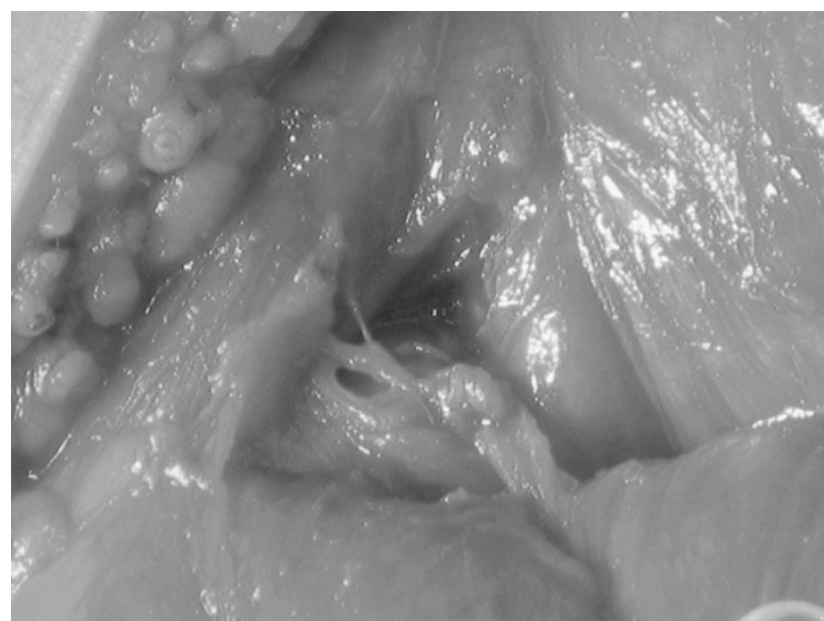

Figure 2 Peroperative view of the m. semimembranosus rupture.

exercise has shown that type II fibers are also more sensitive to mechanical stress. ${ }^{4}$ The extracellular matrix has an important supportive role in skeletal muscle. Recent studies suggest that the extracellular matrix changes seen in the spastic muscle may explain its reduced mechanical properties. The extracellular matrix becomes less elastic compared with control muscle, and is increased in volume. The collagen fibers, however, are much less structured and are much more fragile. ${ }^{3}$ In persons with a spinal cord injury, anesthesia below the level of lesion is an intrinsic risk factor. Reduced or absent pain sensation, in combination with paresis renders apprehensive reactions impossible. Therapeutic stretching, necessary to prevent contractures and to maintain functionality (for example, wheelchair transfer) is an extrinsic risk factor. This could be related to the preference of these muscle ruptures for adductor muscles and the hamstrings. $\mathrm{M}$. semimembranosus rupture is not the most common hamstrings rupture, but has been shown to be specifically vulnerable in slow stretching of the hamstrings. ${ }^{5}$

Reduced effect of antispasmodics and pronounced stiffness at longer muscle lengths are probably indicators of severe secondary compensatory changes in the spastic muscle. Initial rest, ice, compression and elevation have an important role in the outcome of classic muscle tears. In spinal cord-injured patients, the diagnosis may be postponed, given cardinal symptoms such as pain and reduced function are not always noticed or present.

\section{CONCLUSION}

To the authors' knowledge, this is the first report of muscle rupture due to spasticity in SCI patients. Altered mechanical properties of the spastic muscle in combination with extreme stretching can cause complete rupture of the spastic muscle. The necessity of therapeutic stretching in prevention of muscle contractures outweighs the risks of muscle tears. Although this is a rare complication of spasticity, medical staff and therapists should be aware of this risk in order to prevent and rapidly identify the lesion.

\section{CONFLICT OF INTEREST}

The authors declare no conflict of interest.

1 Karen Chua SG, Kong KH. Complete semimembranosus rupture following therapeutic stretching after a traumatic brain injury. Brain Injury 2006; 20: 669-672.

2 PatejdI R, Winkelmann A, Benecke R, Zettl UK. Muscle rupture caused by exacerbated spasticity in a patient with multiple sclerosis. J Neurol 2008; 255: 115-118.

3 Olsson MC, Krüger M, Meyer LH, Ahnlund L, Gransberg L, Linke WA et al. Fibre typespecific increase in passive muscle tension in spinal cord-injured subjects with spasticity. J Physiol 2006; 577: 339-352.

4 Fridén J, Sjöström M, Ekblom B. Myofibrillar damage following intense eccentric exercise in man. Int J Sports Med 1983; 4: 170-176.

5 Askling CM, Tengvar M, Saartok T, Thorstensson A. Acute first time hamstrings strains during slow speed stretching. Am J Sports Med 2007; 35: 1716-1724. 